\title{
Article
}

\section{Sign-speaking: The structure of simultaneous bimodal utterances}

Zeshan, Ulrike and Panda, S

Available at http://clok.uclan.ac.uk/16771/

Zeshan, Ulrike ORCID: 0000-0002-8438-3701 and Panda, S (2018) Signspeaking: The structure of simultaneous bimodal utterances. Applied Linguistics Review, 9 (1).

It is advisable to refer to the publisher's version if you intend to cite from the work. http://dx.doi.org/10.1515/applirev-2016-1031

For more information about UCLan's research in this area go to http://www.uclan.ac.uk/researchgroups/ and search for < name of research Group>.

For information about Research generally at UCLan please go to http://www.uclan.ac.uk/research/

All outputs in CLoK are protected by Intellectual Property Rights law, including Copyright law. Copyright, IPR and Moral Rights for the works on this site are retained by the individual authors and/or other copyright owners. Terms and conditions for use of this material are defined in the policies page.

\section{CLoK}

Central Lancashire online Knowledge www.clok.uclan.ac.uk 
Sign-speaking: The structure of simultaneous bimodal utterances

Ulrike Zeshan \& Sibaji Panda

University of Central Lancashire, Preston, UK 
Abstract: We present data from a bimodal trilingual situation involving Indian Sign Language (ISL), Hindi and English. Signers are co-using these languages while in group conversations with deaf people and hearing non-signers. The data show that in this context, English is an embedded language that does not impact on the grammar of the utterances, while both ISL and Hindi structures are realised throughout. The data show mismatches between the simultaneously expressed ISL and Hindi, such that semantic content and/or syntactic structures are different in both languages, yet are produced at the same time. The data also include instances of different propositions expressed simultaneously in the two languages. This under-documented behaviour is called "sign-speaking" here, and we explore its implications for theories of multilingualism, code-switching, and bilingual language production.

Keywords: Bimodal bilingualism; Indian Sign Language; Hindi; Matrix Language model; community of practice; language production 
1 Introduction and background

This article reports on a particular sub-type of bilingual behaviour, the simultaneous coproduction of signing and speaking. Unlike in the case of bilingualism involving two alternating spoken languages, signing and speaking use different articulatory channels that are largely independent of each other. Therefore, bilinguals who know both a signed and a spoken language may use spoken words co-occurring with manual signs simultaneously. We investigate a contact situation involving Indian Sign Language (ISL), Hindi, and English. The research focuses on the grammatical and semantic contributions that each of these languages make to the trilingual output at the level of the clause. In so doing, we explore the limits of existing explanatory frameworks, such as models of code-switching (with languages seen as separate entities) and translanguaging (with its focus on the deployment of complex linguistic repertoires). The present research is situated within types of bilingualism associated with sign languages (Section 1.1), with a particular interest in the contributions made by each language to the grammar of utterances (Section 1.2).

\subsection{Unimodal and bimodal bilingualism}

The vast majority of the literature on bilingualism is concerned with unimodal bilinguals who use more than one spoken language. More recently, unimodal sign bilinguals, who use more than one sign language, have also been the subject of research (Adam, 2012a; Quinto-Pozos \& Adam, 2015). Available studies involve Mexican Sign Language and American Sign Language (ASL) (Quinto-Pozos, 2002); British Sign Language and Irish Sign Language (Adam, 2012b); and Burundi Sign Language and Indian Sign Language (Zeshan \& Panda, 2015). 
For the purpose of this article, we differentiate between situations where only spoken languages or only sign languages are involved (“unimodal”) and situations where sign languages are co-used with spoken languages ("bimodal"). This is not to deny that in fact, multimodality is very much part of any linguistic performance (cf. Meier, Cormier \& QuintoPozos, 2002; Gullberg, 2011); for instance, speakers use co-speech gesture while speaking, and signers use mouth movements derived from spoken language words while signing (see further in Section 3.2).

Unimodal sign bilinguals behave in many ways like spoken language bilinguals, in particular with respect to code-switching, i.e. the sequential alternation between both languages (Muysken, 2000; Myers-Scotton, 2002), although there are some differences. For instance, both Quinto-Pozos (2002) and Zeshan and Panda (2015) report that there is a substantial degree of lexical overlap between the two sign languages in question, in part due to the shared iconicity of signs. This often makes it difficult to determine which sign language a particular sign in an utterance should be assigned to, and consequently causes difficulty in determining the switch points from one language into another during codeswitching.

The category of bimodal bilingual behaviour involves co-use of (at least) one sign language and (at least) one spoken language. In this article, "bilingualism" shall include multilingual situations with more than two languages, in this case ISL, Hindi, and English. In the literature, research often focuses on hearing people who have deaf parents (known in the sign language literature as CODAs, Children of Deaf Adults), and who have therefore grown up using both sign and speech (Emmorey, Borinstein \& Thompson, 2005, on ASL and English). Recent studies include Donati and Branchini (2012, 2013) on CODA children using Italian Sign Language (LIS) and spoken Italian; Quadros, Lillo-Martin, Koulidobrova and 
Chen Pichler (2013) on young children with deaf parents in the US and in Brazil; and van den Bogaerde and Baker (2006) on spoken Dutch and Sign Language of the Netherlands.

Some previous work on unimodal sign bilingualism has recognised the additional complexities of multilingual situations. Quinto-Pozos $(2002,2008)$ makes reference to the quadrilingual situation of language contact between Spanish, English, ASL, and Mexican Sign Language. Zeshan and Panda (2015) mention the complex multilingual profiles of sign language users from Burundi who live in India. On the other hand, bimodal multilingual situations involving more than two languages are, to our knowledge, undocumented in the literature.

Irrespective of their location and setting, sign languages are always minority languages that exist in close contact with majority spoken (and usually also written) languages. Therefore, it is natural that signed and spoken languages can combine in ways such that the spoken language, as the socially dominant language, has more influence on the signed language than vice versa. That is, signing may be modified and co-produced in parallel with spoken language, and the resulting output is known by terms such as "Sign

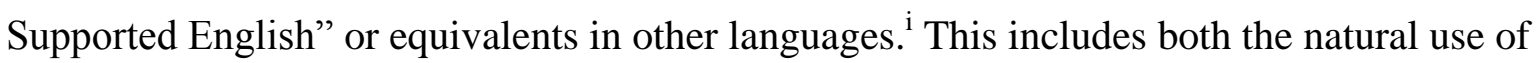
blended features from sign and speech, and the deliberate contrived use of features from both languages for pedagogical purposes in deaf education, with the latter giving more prominence to spoken language structures (cf. Wilbur \& Petersen, 1998). The data reported here are different in that the structures of both grammatically relevant languages, ISL and Hindi, are largely intact.

Two common language contact phenomena are known as "fingerspelling" and "mouthing" in the sign language literature. Fingerspelling involves use of a manual alphabet to quote written words from the spoken language (Zeshan, 2000; Kubus, 2008; Kubus \& Hohenberger, 2011). Each letter of the alphabet is represented by a one- or two-handed 
handshapes or signs, which articulated in sequence spell out words. Mouthing involves making mouth movements, usually silently without use of the voice, that mirror the articulatory movements made when speaking a corresponding word (e.g. mouthing Auto when signing CAR in German Sign Language). Mouthings are integrated with manual signing to a greater or lesser extent, varying both within and across sign languages (see Boyes Braem \& Sutton-Spence, 2001).

1.2 The role of grammar in simultaneous combinations of sign and speech In principle, bimodal bilinguals could engage in the same kind of code-switching as unimodal bilinguals, that is, by alternating sequentially between signing and speaking. Composite utterances of this kind were found in data from young CODA children in Brazil and the US (Quadros, Lillo-Martin, Koulidobrova \& Chen Pichler, 2013), but seem to be uncommon in older signers. Usually, people are either signing or speaking as the dominant modality, and accompany this simultaneously with elements from the other modality.

The simultaneous occurrence of signs and spoken words is called code-blending (Emmorey, Borinstein, Thompson \& Gollan, 2008; Donati \& Branchini, 2012). In order to frame the understanding of our data, it is useful to categorise code-blended utterances into four basic types (a-b here and c-d further below) in terms of the contribution of both languages' grammars to clause-level structure:

a) Speech is the dominant modality. The grammar of the utterance is essentially that of the spoken language, with accompanying signs aligned with the corresponding words (as in the abovementioned Sign Supported English).

b) Signing provides the grammar of the clause, and spoken words are aligned with the signed utterance. This is similar to the abovementioned (silent) mouthing, but in codeblending, the words are spoken out loud. 
These options are compatible with Myers-Scotton's (2002) framework of a Matrix Language (ML) providing the grammatical frame and an Embedded Language (EL) providing only lexical material. The argument in Myers-Scotton (2002) is that in (sequential) codeswitching, only one language provides the grammar of the clause. This can also be applied to simultaneous productions of sign and speech, and options a) and b) are both attested in our data. As previous research has noted (e.g. Lucas \& Valli, 1992; Schembri, 2010), it is useful to posit a continuum of styles with flexible combinations of features from both modalities; hence options a) and b) are in fact situated on the opposite end points of such a continuum.

c) Sign and speech happen to have parallel word/constituent orders (though the internal morphology of signs/words may be different). Again, there is a correlate in sequential code-switching, and Muysken (2000) terms this type congruent lexicalisation. Congruent lexicalisation constitutes an enabling environment for code-switching.

d) The final option is where the signed and spoken language both keep their individual, and incompatible, grammatical structures. This results in structural mismatches between the languages.

Example (1) from Donati and Branchini (2012, p. 109) ${ }^{\mathrm{ii}}$ demonstrates a syntactic mismatch between the signed clause (with clause-final question word) and the spoken clause (with clause-initial question word).

$\begin{array}{lll}\text { It. } & \text { Chi ha chiam-ato? } \\ & \text { who have.PRS.3SG call-PRT } \\ \text { LIS } & \text { CALL } & \text { WHO } \\ & \text { "Who has called?" } & \end{array}$


In semantic mismatches, co-occurring signs and spoken words in a code-blended utterance do not have parallel meanings. In example (2) from Ergenç, İşsever, Makaroğlu and Dikyuva (2014), two semantically (and syntactically) different items co-occur (inflected verb 'watch' in Turkish, and 'film' in TiD).

$$
\begin{aligned}
& \text { Tr. Ben de gid-ip izle -me-di -m. } \\
& \text { I too go-PRT watch-neg-PST-1SG } \\
& \text { TID BEN GITMEK FILM DEĞİL } \\
& \text { I GO FILM NOT }
\end{aligned}
$$

"Having gone (there), I did not watch the film."

In the data analysed for the present study, code-blending shows a high degree of structural integrity of co-occurring languages, and we use the term sign-speaking for this phenomenon. Sign-speaking is defined as simultaneous bimodal language production where a) for the large majority of utterances, neither the signed nor the spoken output is grammatically compromised, and b) utterances include frequent syntactic and/or semantic mismatches.

After discussing the occurrence of English in the data (Section 3.1), the simultaneous combination of ISL and Hindi is addressed in Section 3.2 and Section 4. To provide some background, Table 1 lists some typological differences between ISL and Hindi; this is for illustrative purposes and not intended to be exhaustive (see Sinha, 2008; Aboh, Pfau \& Zeshan, 2006; Zeshan, 2004a on these aspects of ISL grammar). Constituent order is particularly important - unlike conversational spoken Hindi, ISL has strict constituent orders with respect to some clause constituents. The morphological structures of ISL and Hindi are radically different from each other. Therefore, signs and words with parallel meanings but different internal structures often co-occur in the data. 
Table 1. Some characteristics of ISL and Hindi.

\begin{tabular}{lll}
\hline $\begin{array}{l}\text { Sequential inflectional } \\
\text { morphology (nominal) }\end{array}$ & $\begin{array}{l}\text { Hindi } \\
\text { case, number, gender }\end{array}$ & ISL \\
\hline $\begin{array}{l}\text { Sequential inflectional } \\
\text { morphology (verbal) }\end{array}$ & $\begin{array}{l}\text { Highly inflectional, incl. } \\
\text { tense, aspect, aktionsart, } \\
\text { causative }\end{array}$ & $\begin{array}{l}\text { Very little; no } \\
\text { morphological tense }\end{array}$ \\
\hline Adpositions & Postpositions & None \\
\hline $\begin{array}{l}\text { Simultaneous morphology } \\
\text { (non-spatial) }\end{array}$ & None & $\begin{array}{l}\text { Some, incl. aktionsart, } \\
\text { compounding }\end{array}$ \\
\hline $\begin{array}{l}\text { Simultaneous morphology } \\
\text { (spatial) }\end{array}$ & None & $\begin{array}{l}\text { Highly inflectional, incl. } \\
\text { verb agreement, aktionsart, } \\
\text { classifiers, auxiliary }\end{array}$ \\
\hline $\begin{array}{l}\text { Clause constituent order } \\
\text { Placement of wh-question }\end{array}$ & $\begin{array}{l}\text { Basic SOV, but high degree } \\
\text { of flexibility, esp. in } \\
\text { conversational speech }\end{array}$ & $\begin{array}{l}\text { Fixed constituent orders: } \\
\text { predicate-final; clause-final } \\
\text { functional particles }\end{array}$ \\
\hline $\begin{array}{l}\text { Placement of basic clause } \\
\text { negator }\end{array}$ & Unmarked order pre-verbal & Obligatorily clause-final \\
\hline $\begin{array}{l}\text { Compound verbs, copula } \\
\text { verbs }\end{array}$ & Yes & Obligatorily clause-final \\
\hline
\end{tabular}

Moreover, ISL and Hindi also differ at the lexical level. Thus there is not always a translation equivalent available for individual signs and words, and even if translation equivalents exist at the level of individual lexemes, collocations may be different.

\section{Data and methodology}

\subsection{Participants and fieldsite setting}

The participants in this study are four hearing individuals associated with a school for the deaf in central India, the Indore Bilingual Academy, were they all held professional roles at the time of data collection. Data collection took place in the school setting over three consecutive days. All participants are highly fluent in ISL and Hindi, and also acquired 
English through formal education. Three participants have deaf parents, and two have additional deaf relatives. The participants use ISL and Hindi regularly in professional contexts (see profiles in Table 2).

Table 2. Participant profiles.

\begin{tabular}{|c|c|c|c|c|}
\hline & $\mathrm{P} 1$ & $\mathrm{P} 2$ & P3 & $\mathrm{P} 4$ \\
\hline Age & 23 & 31 & 21 & 30 \\
\hline Education level & Master's & Master's & Bachelor's & Bachelor's \\
\hline Occupation & $\begin{array}{l}\text { Teacher and sign } \\
\text { language interpreter }\end{array}$ & $\begin{array}{l}\text { Director of ISL } \\
\text { department, sign } \\
\text { language } \\
\text { interpreter and } \\
\text { trainer }\end{array}$ & $\begin{array}{l}\text { Student and } \\
\text { freelance sign } \\
\text { language } \\
\text { interpreter }\end{array}$ & $\begin{array}{l}\text { Administrator and } \\
\text { sign language } \\
\text { interpreter }\end{array}$ \\
\hline $\begin{array}{l}\text { Native languages } \\
\text { (L1) }\end{array}$ & Hindi & ISL and Hindi & ISL and Hindi & ISL and Hindi \\
\hline $\begin{array}{l}\text { Second languages } \\
\text { (L2) }\end{array}$ & ISL, English & $\begin{array}{l}\text { English, American } \\
\text { Sign Language, } \\
\text { International Sign }\end{array}$ & English & $\begin{array}{l}\text { English, American } \\
\text { Sign Language, } \\
\text { International Sign } \\
\end{array}$ \\
\hline $\begin{array}{l}\text { L2 age of } \\
\text { acquisition }\end{array}$ & $\begin{array}{l}\text { ISL: } 16 \\
\text { English: } 4\end{array}$ & $\begin{array}{l}\text { English: } 4 \\
\text { American Sign } \\
\text { Language and } \\
\text { International Sign: } \\
25\end{array}$ & English: 3 & $\begin{array}{l}\text { English: } 10 \\
\text { American Sign } \\
\text { Language and } \\
\text { International Sign: } \\
24\end{array}$ \\
\hline $\begin{array}{l}\text { Deaf family } \\
\text { members }\end{array}$ & None & $\begin{array}{l}\text { Both parents, } \\
\text { uncle, in-laws }\end{array}$ & Both parents & Father, in-laws \\
\hline $\begin{array}{l}\text { ISL contexts of } \\
\text { use }\end{array}$ & $\begin{array}{l}\text { ISL used in } \\
\text { everyday life and at } \\
\text { work }\end{array}$ & $\begin{array}{l}\text { ISL used in } \\
\text { everyday life and } \\
\text { at work }\end{array}$ & $\begin{array}{l}\text { ISL used in } \\
\text { everyday life and } \\
\text { at work }\end{array}$ & $\begin{array}{l}\text { ISL used in } \\
\text { everyday life and at } \\
\text { work }\end{array}$ \\
\hline $\begin{array}{l}\text { Reported co-use } \\
\text { of signing and } \\
\text { speaking }\end{array}$ & Sometimes & Often & Often & Often \\
\hline
\end{tabular}

Although all participants also work as sign language interpreters, this is not their only or even their main role in the school setting. In India, sign language interpreting is only just becoming more professionalised very recently, and the delineation of roles, e.g. between teacher, administrator, counsellor, and interpreter, is quite weak, leaving considerable room for fluidity. The practice of sign-speaking is closely related to a widespread unavailability of people functioning specifically as sign language interpreters. In combination with the prominence of ISL at the school, this setting prompts hearing people with a high level of sign 
language skills to express both languages simultaneously. This kind of situation is not welldocumented, and we are not aware of other work describing the structural characteristics of what we call sign-speaking here.

The data were collected by co-author Panda, a deaf researcher with native fluency in ISL, who has worked in professional contexts involving sign language in India for the past 15 years. He has had long-standing contact with the deaf school, which enabled easy access into the field setting. The Indore Bilingual Academy is one of the largest deaf schools in India, with 600 students, including hostel places for 350 students, ranging in age from three to the early 30s. Most students study up to class X or class XII, often graduating with several years' delay due to unstable educational biographies (the normal age for completing secondary schooling in India after class XII is around 17 years). ISL is ubiquitous at the school during assemblies, mealtimes, and leisure times, as well as in the classrooms and dormitories, while Hindi is the predominant spoken/written language. All teachers have various degrees of fluency in ISL. Several subject teachers, some teaching assistants, and many support staff are deaf ISL users.

The fieldwork methodology is inspired by the ethnographic technique of focal following, which is common in anthropology and has also been used in research with deaf communities (see Nonaka, 2012, on such work in Thailand). The researcher identifies a particular individual of interest and spends an entire day or several days shadowing this person. This is a way to gain insight into the individual's daily life routines, social networks, and communicative practices.

The participants were briefed about the aims of the research and the plans for filming during focal following. All participants then signed a consent form detailing permissible use of their video data. In addition, they completed a background questionnaire in English with detailed information about their linguistic experience as bilinguals. 


\subsection{Data collection and analysis}

During fieldwork it was largely unpredictable when a suitable bimodal-bilingual setting would arise. Therefore, focal following allowed the researcher to be ready with the camera whenever an interaction with deaf people and hearing non-signers might prompt signspeaking behaviour, and this technique was very fruitful for data collection. It was our aim to sample naturally arising situations, avoiding as much as possible any artificial or contrived aspects of the settings. Co-author Panda's familiarity with the field site was key to selecting suitable naturalistic settings, and gently adjusting others to match the research aim. In one instance (segments 18-19) additional deaf participants were asked to join the interaction, and in segments $12-14$, an interpreter was sent away in order to enable sign-speaking in a formal environment. In general though, mixed audiences were readily available. In fact, as issues of confidentiality (for example when counselling students and their parents) do not operate in this environment in the same way as in Western countries, the presence of various bystanders who can constitute mixed deaf-hearing audiences for the targeted interactions is very common and largely unproblematic.

Prior to each instance of filming, everyone present in addition to the participants was informed about the research and the intended use of the camera. Hearing people were made aware that their voice would be audible on the video, but only the sign-speaker was videotaped. Although it would have been more informative to videotape all participants in the interaction, this would have disturbed the spontaneity of the situation because of the need to gain informed consent from all individuals present in advance of filming, which would have taken additional time and disrupted people's schedule and time commitment. Finally, the less intrusive use of the camera further contributed to minimising the observer's paradox, avoiding any potential anxiety on the part of the sign-speaker's audience. 
Nearly 1.5 hours of video data (78 mins 40 secs) were collected in this way, with a total of eight episodes of bimodal-bilingual communication between two and 13 minutes long. An episode is defined as an uninterrupted situation occurring at one particular time with the same set of participants, including at least one sign-speaker. One of the sign-speakers participated in only one episode, while the three others each appear in several episodes. Not all video data fit our definition sign-speaking, as sign-speakers also used Hindi and ISL separately at times. One complete episode was excluded on the basis that the interaction involved translating English into Hindi/ISL sign-speaking, which adds another level of complexity.

From among those video segments that qualify as sign-speaking, we have focused on monologue segments of 30 seconds' duration or longer. This is because the interest here is on the linguistic properties of sign-speaking rather than on the interactions between participants. In the interactions, we often find interesting sequencing of monolingual and bimodalbilingual productions, as the sign-speakers also interpret between the deaf and the hearing participants in addition to addressing the entire mixed audience. As mentioned above, there is no clear delineation between being an interpreter and being a participant (e.g. a counsellor for the deaf student and the hearing parents) in the interaction.

The longer monologue segments comprise over half an hour of recordings in total. For annotation of the data, the ELAN computer program was used (Wittenburg, Brugman, Russel, Klassmann \& Sloetjes, 2006). This program allows time-aligned annotations to be linked to a video. Annotations are presented on several tiers whose functionality can be assigned flexibly by the researcher (see Figure 1). 


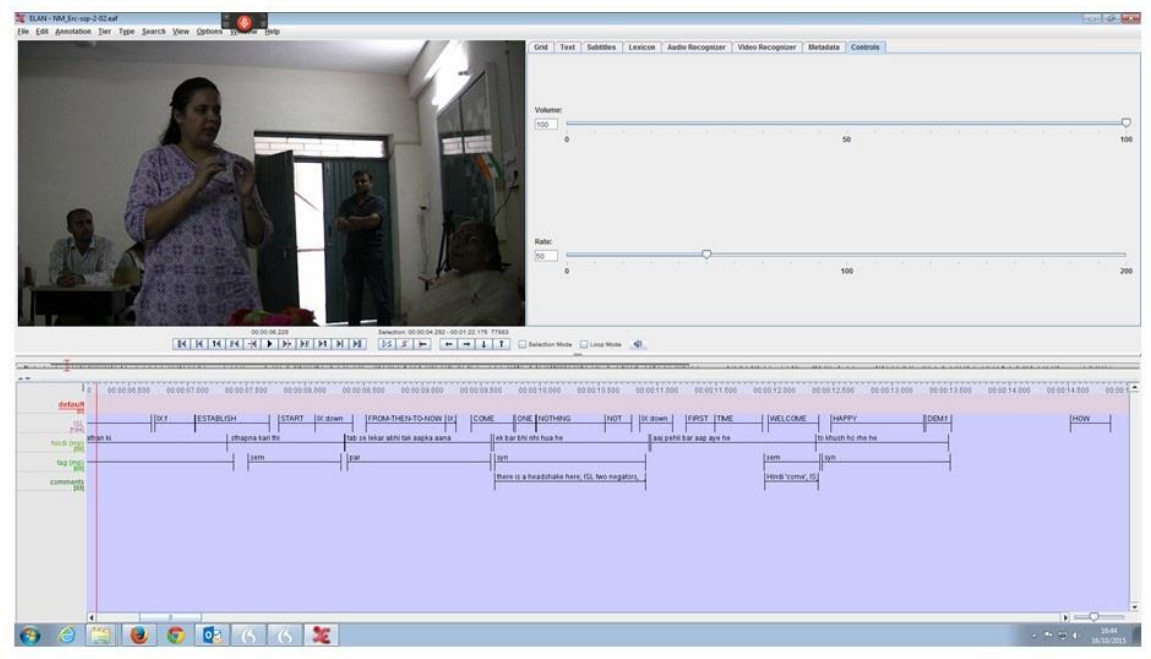

Figure 1

The annotations include the following tiers, all of which are time-aligned in ELAN:

ISL: Word-by-word glossing of signs in English based on the sign's meaning in context (one annotation per sign);

Hindi: Full-text transcript, using the Roman alphabet (one annotation per intonational phrase);

Tag: Coding system for the relationship between ISL and Hindi (see Sections 3.2 and 4); Comment: Any other observations.

The unit of annotation and coding is the clause, as we were particularly interested in the relationship between simultaneously produced signing and speaking at the level of the clause. These clause units include both monoclausal main clauses and complex clauses that are combinations of main and subordinate clauses; that is, we do not differentiate between simple and complex clauses in the analysis. In Hindi, clauses are identified on the basis of morphosyntax, that is, as having a single inflected verb form in a main clause. For ISL, identifying clause boundaries is more challenging because the only obligatory constituent of 
clauses is the predicate, and many types of signs can function as predicates. Therefore, clauses are identified on semantic grounds as constituting complete (simple or complex) predications, in combination with one or several of the following: the presence of a functional particle, of which each ISL clause can have only one, in clause-final position (cf. Zeshan \& Panda 2015 on ISL clause structure); a clear intonation break (in line with Sandler 1999); or parallel production with the identified Hindi clause in the case of ISL clauses that are partial or adapted in parallel with Hindi. The latter principle also applies, vice versa, to Hindi clauses that are partial or adapted to ISL clause structures (see Section 3.2 on partial and adapted structures).

In addition, we were interested in the occurrence of English words and phrases in the data. These were entered into an Excel file and grouped into the following coding categories:

- Whether single word (W) or phrase (P)

- Whether content word (C) or function word (F); a phrase may consist of either C or F or both

- Whether occurring together with fingerspelling (FS)

Table 3 provides a data summary. Data coding for English covers all segments listed in the table. Data coding with ELAN, which is a very time-consuming process, was done for six texts of 30 clauses each, resulting in a total of 180 clauses. These include texts from all four participants, as well as more formal text types (explanatory, presentative), less formal types (personal narratives, personal counselling), and varying constellations of addressees. 
Table 3. Data summary

\begin{tabular}{|c|c|c|c|c|c|}
\hline Segment & Duration & $\begin{array}{l}\text { Sign- } \\
\text { speaker }\end{array}$ & Topic & $\begin{array}{l}\text { Coding for } \\
\text { English }\end{array}$ & $\begin{array}{l}\text { Coding for } \\
\text { ISL \& } \\
\text { Hindi }\end{array}$ \\
\hline 1 & 01:48 & 1 & $\begin{array}{l}\text { Counselling about life chances for } \\
\text { deaf people }\end{array}$ & all & $\begin{array}{l}01: 33 \\
30 \text { clauses }\end{array}$ \\
\hline 2 & $01: 55$ & 1 & $\begin{array}{l}\text { Relating a story from sign language } \\
\text { course materials }\end{array}$ & all & $\begin{array}{l}01: 18 \\
30 \text { clauses }\end{array}$ \\
\hline 3 & $01: 38$ & 1 & $\begin{array}{l}\text { Counselling about importance of } \\
\text { hearing parents learning ISL }\end{array}$ & all & \\
\hline 4 & $01: 25$ & 1 & $\begin{array}{l}\text { Counselling about sign language } \\
\text { communication in the family }\end{array}$ & all & \\
\hline 5 & 01:46 & 1 & Personal experience of learning ISL & all & \\
\hline 6 & 01:09 & 1 & $\begin{array}{l}\text { Information about the deaf school } \\
\text { hostel }\end{array}$ & all & \\
\hline 7 & $00: 41$ & 1 & $\begin{array}{l}\text { Information about studying at the } \\
\text { deaf school }\end{array}$ & all & \\
\hline 8 & $00: 46$ & 1 & Additional tuition and study support & all & \\
\hline 9 & $00: 41$ & 1 & Study and exams, especially maths & all & \\
\hline 10 & $00: 52$ & 1 & $\begin{array}{l}\text { Advice about the importance of } \\
\text { maths }\end{array}$ & all & \\
\hline P1 & 11:36 & Total & & & \\
\hline 11 & $02: 34$ & 2 & $\begin{array}{l}\text { Explanations about the ISL diploma } \\
\text { course }\end{array}$ & all & \\
\hline 12 & $00: 43$ & 2 & $\begin{array}{l}\text { Presentation to visitors, introducing } \\
\text { the school }\end{array}$ & all & \\
\hline 13 & $03: 38$ & 2 & $\begin{array}{l}\text { Presentation to visitors, further } \\
\text { information about the school }\end{array}$ & all & $\begin{array}{l}01: 23 \\
30 \text { clauses }\end{array}$ \\
\hline 14 & 02:09 & 2 & $\begin{array}{l}\text { Presentation about extracurricular, } \\
\text { vocational \& ISL dept activities }\end{array}$ & all & \\
\hline $\mathbf{P 2}$ & 09:04 & Total & & & \\
\hline 15 & 01:38 & 3 & $\begin{array}{l}\text { About learning ISL as a first } \\
\text { language }\end{array}$ & all & \\
\hline 16 & $05: 21$ & 3 & $\begin{array}{l}\text { Views about the importance of deaf } \\
\text { culture and sign language }\end{array}$ & all & \\
\hline 17 & $02: 15$ & 3 & $\begin{array}{l}\text { Counselling about life chances for } \\
\text { deaf people }\end{array}$ & all & $\begin{array}{l}00: 41 \\
30 \text { clauses }\end{array}$ \\
\hline 18 & $00: 46$ & 3 & Advice about joining an ISL course & all & \\
\hline 19 & $04: 25$ & 3 & $\begin{array}{l}\text { Personal experiences of growing up } \\
\text { with deaf parents as a hearing child }\end{array}$ & all & $\begin{array}{l}00: 41 \\
30 \text { clauses }\end{array}$ \\
\hline $\mathbf{P 3}$ & $14: 25$ & Total & & & \\
\hline 20 & 00:38 & 4 & $\begin{array}{l}\text { Information about sign language } \\
\text { interpreting courses }\end{array}$ & all & \\
\hline 21 & 01:07 & 4 & $\begin{array}{l}\text { Interpreting and other work with } \\
\text { sign language }\end{array}$ & all & $\begin{array}{l}01: 02 \\
30 \text { clauses }\end{array}$ \\
\hline 22 & $01: 12$ & 4 & $\begin{array}{l}\text { About sign language dictionaries } \\
\text { and 3-D technology }\end{array}$ & all & \\
\hline 23 & $00: 41$ & 4 & $\begin{array}{l}\text { About technologies with sign } \\
\text { language applications }\end{array}$ & all & \\
\hline $\mathbf{P 4}$ & 03:38 & Total & & & \\
\hline All & 38:54 & Total & & & \\
\hline
\end{tabular}


3 Characteristics of linguistic output in sign-speaking

3.1. The trilingual situation

The context of this research is a trilingual situation with two spoken languages (English and Hindi) and ISL. In addition, two of the participants have competence in another sign language (ASL) and a semi-conventionalised signed pidgin (International Sign; see Hiddinga \& Crasborn, 2011). Individual signs of ASL origin appear very occasionally, and these are highfrequency items that are used by some deaf Indians as loans. However, none of these signs are function words or affect the grammar of the utterance.

An important initial observation is that the three contributing languages are not of equal status in the linguistic output. Specifically, English contributes only at the level of individual lexemes and phrases, and there are virtually no complete utterances in English by the sign-speakers anywhere in the data. The only exception is a performative "That is all; thank you." at the end of an episode. Moreover, there is virtually no contribution to the grammar of utterances from English.

Table 4. English words and phrases in the data

\begin{tabular}{lllc}
\hline & Single word (W) & Phrase (P) & Totals \\
\hline Content word (C) & 645 & 150 & 795 \\
\hline Function word (F) & 4 & 1 & 5 \\
\hline Content and function word (FC) & - & 9 & 9 \\
\hline Totals & 649 & 160 & 809 \\
\hline
\end{tabular}


As Table 4 shows, only $1.7 \%$ of English words and phrases involve any function words, nearly all of which are coordinating conjunctions. This includes but, and then, as well as plus which is used instead of and several times. Moreover, the only inflected forms found in the data are nominal plurals. Overwhelmingly, single words are slotted into the ISL/Hindi sign-speaking text (80\% single words); that is, they are instances of insertion as defined in Muysken (2000). 68\% of English words and phrases consist of nouns, nominal compounds, and NPs, with the rest covering all other word classes. The few English verb-direct object combinations $(0.6 \%)$ appear in Hindi O-V constituent order. These facts support the conclusion that English does not contribute to the grammar of utterances at clause level.

This pattern cannot be explained simply by the lack of English competence among the hearing addressees. While some of them are not competent in spoken English, this is not always the case. In fact, hearing participants other than the sign-speaker can occasionally be heard speaking English in the recordings. There is no noticeable difference between the individual participants with respect to these patterns, and only a small difference with respect to text segments. There is, on average, one English word every 2-3 seconds, with only six texts out of 23 deviating from this pattern (three with higher frequency and three with lower frequency).

Another way in which English appears in the data is via fingerspelling. Use of the manual alphabet is an integral part of many sign languages (e.g. Sutton-Spence, 1994; Hendriks \& Dufoe, 2014; Roos, 2014), and the language of fingerspelling usually matches the dominant surrounding spoken language. However, Indian signers use a two-handed manual alphabet to represent words or proper names from English as well as from Indian languages (in English transliteration). In the data, fingerspelling is used in the same way as spoken English, i.e. its function is purely to represent individual lexical items, often proper 
names and abbreviations but no function words, and there is no effect on the grammar of the utterance. Fingerspelling occurs 34 times and is always accompanied by voicing.

The data support the view that the occurrence of English in these texts conforms to a typical case of Embedded Language in terms of Myers-Scotton (2002), with insertion being the main pattern. On the other hand, the relationship between Hindi and ISL cannot be adequately analysed within this framework, as set out in the remaining sections.

\subsection{Context-sensitive repertoires in sign-speaking}

The defining feature of sign-speaking is a high degree of structural integrity of the simultaneously produced languages. However, within this overall definition, the question arises as to whether one of the grammatically relevant languages (Hindi or ISL) may be more fully expressed than the other in particular discourse segments. To this end, data coding with ELAN included the following codes, which were designed to allow us to identify the instances when one of the languages is not expressed fully.

NO-ISL and NO-HINDI: Utterances are in one language only, with no accompanying signs/words from the other language.

PARTIAL-ISL and PARTIAL-HINDI: A complete utterance in one language is partially accompanied by some signs/words from the other language.

ADAPTED-ISL and ADAPTED-HINDI: ISL signs/Hindi words appear in a nonnative, ungrammatical pattern in order to parallel the structures from the other, grammatically dominant language.

In order to identify adapted ISL or Hindi, grammaticality judgements for ISL are based on the second author's native competence, and those for Hindi are based on the first author's near- 
native competence. No separate grammaticality judgements have been elicited from other signers or speakers.

In previous research on bimodal bilinguals, having one dominant language that provides the grammar of the utterance is the usual option. For instance, in the data from Emmorey et al. (2008), the non-dominant language is often partially represented in the form of individually inserted words or phrases, mostly with English as the dominant language. In the sign-speaking data, the picture is quite different, as utterances with no, partial, or adapted Hindi/ISL constitute only a minority of clauses. $21.7 \%$ of clauses are in this category, with ISL and Hindi equally affected in total.

The data suggest that it is the situational setting that determines which language is more fully represented. This can be inferred from Table 5, which shows the frequency of utterances with no, partial, or adapted Hindi/ISL across the different 30-clause texts from the monologue segments. The data include no clauses where both languages are partially represented.

Table 5. Partially represented utterances

\begin{tabular}{|c|c|c|c|c|}
\hline Segment & $\begin{array}{l}\text { Sign- } \\
\text { speaker }\end{array}$ & Topic & $\begin{array}{l}\text { No/partial/ } \\
\text { adapted Hindi }\end{array}$ & $\begin{array}{l}\text { No/partial/ } \\
\text { adapted ISL }\end{array}$ \\
\hline 1 & 1 & Counselling about life chances for deaf people & 1 & 1 \\
\hline 2 & 1 & Relating a story from sign language course materials & 2 & 2 \\
\hline 13 & 2 & $\begin{array}{l}\text { Presentation to visitors, further information about the } \\
\text { school }\end{array}$ & 0 & 10 \\
\hline 17 & 3 & Counselling about life chances for deaf people & 6 & 3 \\
\hline 19 & 3 & $\begin{array}{l}\text { Personal experiences of growing up with deaf parents } \\
\text { as a hearing child }\end{array}$ & 9 & 0 \\
\hline 21 & 4 & Interpreting and other work with sign language & 3 & 2 \\
\hline
\end{tabular}

Example (4) from segment 13 is from a Hindi-dominant text where only ISL is omitted or adapted, and example (5) from an ISL-dominant text in segment 19 where only Hindi is 
omitted or adapted. In both examples, the choice of dominant language correlates with the primary addressees in the interaction.

(4) - An insurance company is visiting the school to donate a projector. P2 is giving an address to the hearing company staff (who are all non-signers), about 25 hearing school staff, and about 50 deaf people. The hearing visitors are sitting next to P2 on the left; everyone else is in front in the audience. The purpose of the text is to introduce the school and its activities to the visitors. (4a) has partial ISL accompanying a complete Hindi clause. In (4b), ISL word order is adapted to the Hindi clause (SVO instead of the usual ISL verb-final order).

(a) IX:left 3(left):GIVE:3(front) ab jo aaj aap -ki taraf se aap eh present kar-na chah rahe hain now REL today 2.HON-POSS.f side from 2PL.HON present do-INF want PROG.PL.PRS "Now what you want to present (to us) today from your side,"

(b) L-I-C IX:left 3(left):GIVE:3(front)

LIC ki taraf se aap jo dena chah rahe hain

PROJECTOR projector

LIC POSS.f side from 2.HON REL give want PROG.PL.PRS projector "The projector that you want to give..."

(5) - P3 is advising a hearing mother who has a young deaf child attending the school. Also present are two young deaf adults/teenagers who are students there. The students were pulled in ad hoc in order to constitute the deaf part of the audience. One of the deaf participants has asked a question about growing up as a hearing child with deaf parents. Parts of the clause are missing from Hindi in (4a) and (4d), and (4e) has no Hindi at all. In (4c), the Hindi clause is grammatically incomplete because the verbal linker ke should be followed by another main verb. ${ }^{\text {iii }}$

(a)

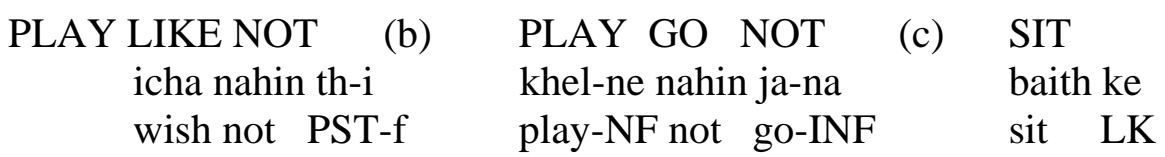

"I didn't feel like playing. I didn't go out to play. I would sit (at home)."

(d) MOTHER BOTH SIGN

baat kar rahe hain

talk do PROG.PL.PRS

(e) IX:1 LOOK-right-left

"My parents would talk in sign language and I would look right and left (from one to the other)."

Due to the partial representation, these examples raise the issue of delimiting mouthing from spoken Hindi, and ISL signs from co-speech gesture. Mouthing as a part of ISL utterances is 
usually silent and consists of individual, uninflected words (Zeshan, 2001). Thus the voiced, inflected phrase baat kar rahe hain ('they are talking') in (5b) is spoken Hindi while mouthing [baat] on its own would be considered part of ISL. As spoken Hindi is highly inflectional, the distinction has not been difficult to make in the data. The main distinguishing factor between ISL signs and formationally identical co-speech gestures is whether the manual form occurs in a context together with other ISL signs, that is, within a multi-sign ISL utterance, or as a single manual item in a co-speech context. Thus the index points at the beginning of examples (4a) and (11) could be interpreted as co-speech gestures; the same is true of complete Hindi clauses accompanied by a single manual sign/gesture, such as Hindi 'That will be good.' with a sign/gesture meaning 'good'. Although such examples are not frequent in our data, this issue does highlight the fact that we are dealing with a multimodal context (on the relationship between sign language pronouns and gestural pointing see Cormier, Schembri \& Woll, 2013 and Johnston, 2013).

As part of the episode that contains segment 13, the sign-speaker makes an interesting meta-communicative comment (translated from ISL and Hindi):

P2: $\quad$ ISL [facing straight ahead]: "It's difficult to keep eye contact with the deaf who are watching me (from the front). There are hearing people here." (...)

Hindi: [turning to the left]: "For speaking, my attention keeps going this way (to the left) because you are the hearing people. [turning back and facing straight ahead]: Those people will watch the signs."

ISL [facing straight ahead]: "I thought it is easy, but I keep focusing over here (left side)."

This comment further supports the view that in some interactions, there are primary and secondary audiences, and that the language of the primary audience skews the bimodalbilingual output in its favour. That is, sign-speakers have a range of bimodal-bilingual styles in their repertoire and can vary their productions on a continuum from more Hindi-like to more ISL-like, depending on the communicative setting. To elucidate this part of the data, it is useful to consider the notion of translanguaging (García \& Wei, 2014). Translanguaging 
focuses on “the deployment of a speaker's full linguistic repertoire without regard for watchful adherence to the socially and politically defined boundaries of named ... languages" (Otheguy, García \& Reid 2015:283), and the notion of "repertoire" is not only multilingual but also explicitly multimodal (Blackledge, Creese \& $\mathrm{Hu}, 2015)$. This notion naturally accommodates features such as co-speech gesture, mouthing and fingerspelling in the signspeakers' performances, which are seen holistically as creatively combined products. This offers a different perspective on the above issue of clearly delimiting ISL features from spoken Hindi features and from co-speech gesture, though distinguishing the "input" languages remains important for the discussion in Section 4.

Besides these more Hindi-like and more ISL-like repertoires, the remaining texts have no bias towards either language. ${ }^{\text {iv }}$ In any case, the notable fact remains that the utterances with omitted or adapted Hindi/ISL are in a minority. This means that for the remaining utterances, we can expect a large number of mismatches between the two languages.

4 Syntactic and semantic mismatches in sign-speaking

For the purpose of analysing grammatical mismatches, we focus on word order in this section, as mismatched word orders are easy to identify and have been subject to investigation in previous research (see Donati \& Branchini, 2012, Ergenç et al., 2014). Some other ways in which the grammars of ISL and Hindi diverge in the bimodal output are mentioned in Section 5.

In the ELAN annotations, utterances have been coded as PAR (parallel utterances without any mismatch) or SYN (syntactic mismatch). Further codes are SEM (semantic mismatch) and SYNSEM (both semantic and syntactic mismatch). 


\subsection{PAR-coded utterances}

PAR-coded utterances are parallel structures that are compatible with the grammars of both languages, and there is no mismatch. The grammatical endings, postpositions, auxiliaries and particles that are characteristic of Hindi but do not occur in ISL are disregarded for the purpose of coding, as are the spatial morphological processes and nonmanual grammatical expressions of ISL that do not occur in spoken Hindi. If we were to compare utterances at the level of each morpheme, virtually all utterances would involve mismatches because of the great differences in the morphological organisation of both languages, and the analysis categories would become meaningless.

Example (6) is characteristic of additional morphological complexity in Hindi that is absent from ISL, including gender, postposition and copula. In example (7), the ISL verb has spatial inflection expressing subject-object agreement with PAY while Hindi has future tense marking.

(6) IX:1 FAMILY DEAF NOTHING

mer $-\mathrm{i}$ family mein deaf koi nahin hai my $-\mathrm{f}$ family in deaf any not COP.PRS.3SG

"There are no deaf (people) in my family." See Figure 2

(7) IX:3 FIVE THOUSAND 1:PAY:3

is-ko five thousand ham pay kar-enge 3SG-OBL five thousand we pay do-FUT.1PL "We will pay him five thousand." 

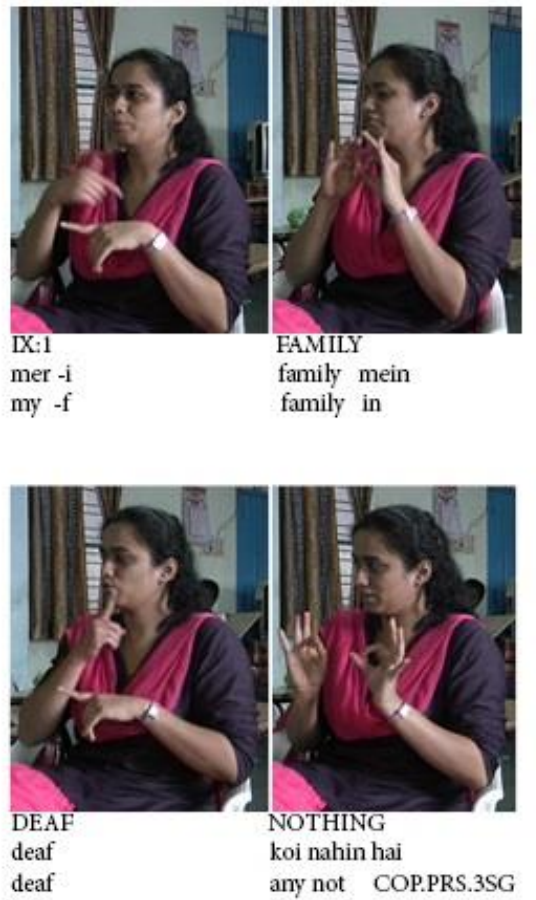

'There are no deaf (people) in my family.'

Figure 2
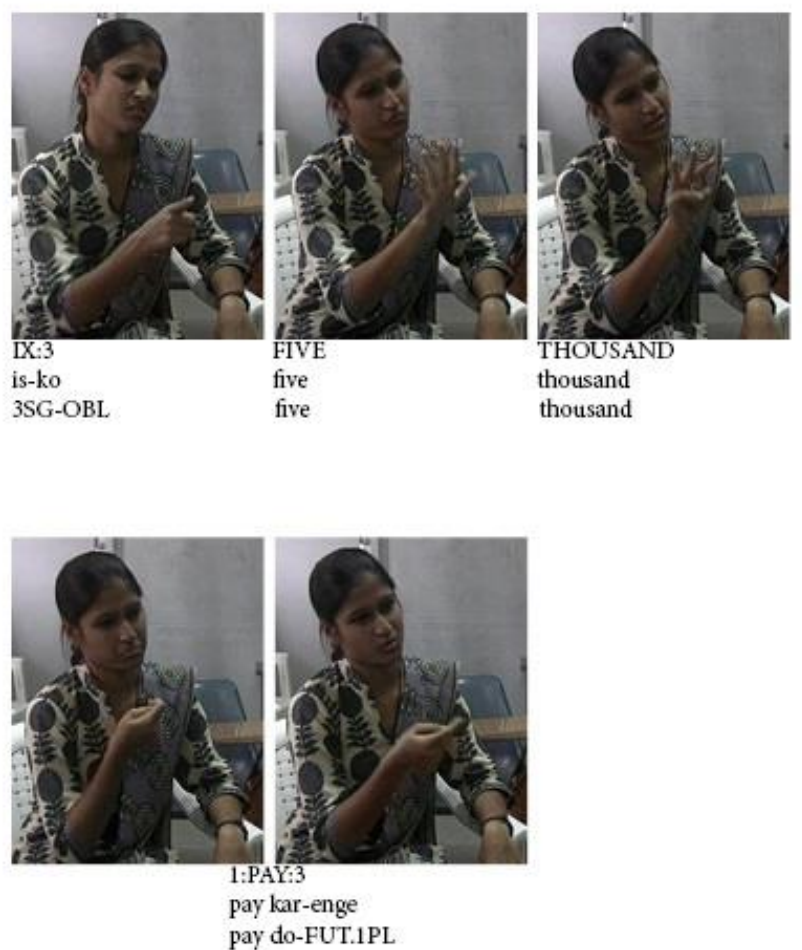

'We will pay him five thousand'

Figure 3 


\subsection{SEM-coded utterances}

The SEM code indicates a semantic mismatch between ISL and Hindi. In these cases, the syntax of both utterances is parallel, but different meanings are expressed in each modality (example 8). Often the two meanings are similar or related, but more divergent meanings also occur.

(8) TODAY FIRST TIME 2:WELCOME:1

aaj pehl-i baar aap aa-e hain

today first-f time you.HON come-NF COP.2PL

"Today you are welcomed here for the first time." (ISL)

"Today you have come here for the first time." (Hindi) See Figure 4

Here the ISL verb means 'welcome' whereas the Hindi verb means 'come'. The Hindi pronoun aap (honorific second person) is equivalent to the verbal inflection of ISL WELCOME, and the copula in Hindi is disregarded, so that there is no syntactic mismatch according to our definition. The overall sense of the two utterances is of course similar, but there is nevertheless a semantic difference.

A semantic mismatch is only coded as such where an ISL sign does have a Hindi correlate, and vice versa, but which is not used in the utterance. Thus Hindi does have a word svagat which is parallel to the ISL sign WELCOME, and ISL does have a sign COME. On the other hand, where no semantic equivalent is available, choosing an appropriate alternative is not regarded as a semantic mismatch. For example, if Hindi kaise ('how') co-occurs with the semantically more general ISL sign glossed WH, this is not coded as a semantic mismatch because ISL does not have any specific sign that means 'how'. Instead, WH is a general interrogative in ISL which includes 'how' as one of its possible meanings (Zeshan, 2004b). 


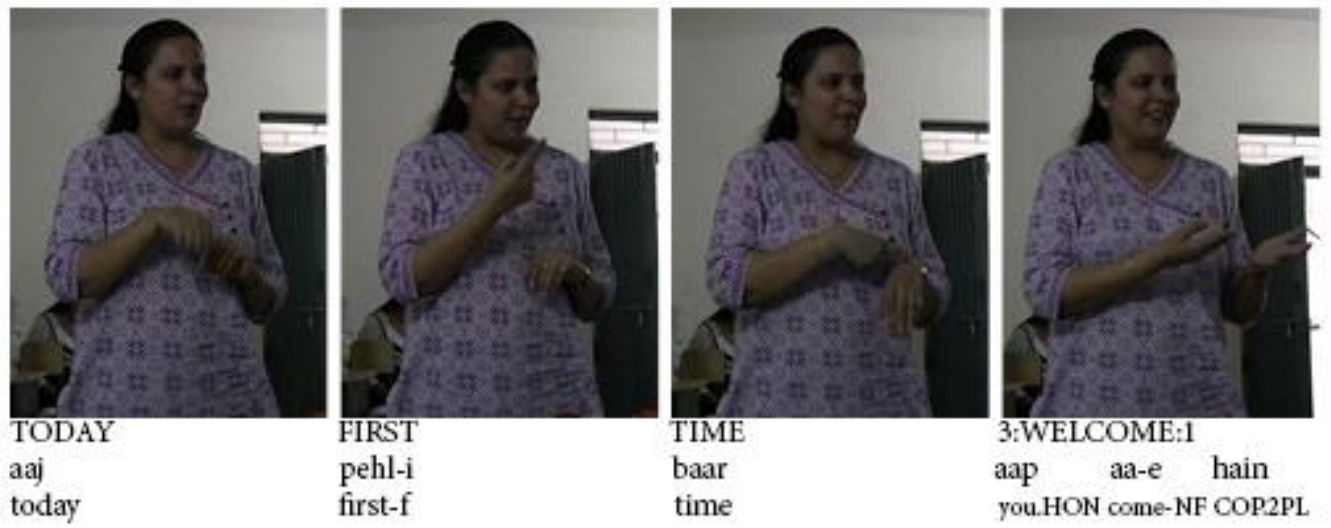

'Today you are welcomed here for the first time.' (ISL)

'Today you have come here for the first time.' (Hindi)

Figure 4

\subsection{SYN-coded utterances}

Syntactic mismatches are defined as instances of semantically equivalent content words appearing in different positions in the clause. In example (9), both utterances include an indefinite (kuch bhi and ANY), a negative, and a word/sign meaning "force" and "good". The Hindi copula and the dummy verb kar-are absent from ISL, which does not have equivalent constructions. The semantic elements are present in both languages, but are distributed differently over the clause. In fact, in ISL the sign NO negates the predicate FORCE, while in Hindi the negation applies to "good".

(9) FORCE $\mathrm{NO}-\mathrm{NO}$

ANY GOOD

kuch bhi force kar-oge to acha nahin ho-ga anything force do-FUT.2SG then good not be-FUT.3SG

"Don't force anything; that is better." (ISL)

"(If) you are going to force anything, that won't be good." (Hindi) See Figure 5 
In example 10, the clauses are temporally misaligned and the ISL sentence starts first with the sign LIFE, while life comes at the end of the Hindi clause.

\section{(10) LIFE EVERYTHING EXIST \\ pur-i dunya ki life hai \\ all-f world POSS.f life COP.PRS.3SG}

"This is life everywhere / for everyone."
See Figure 6

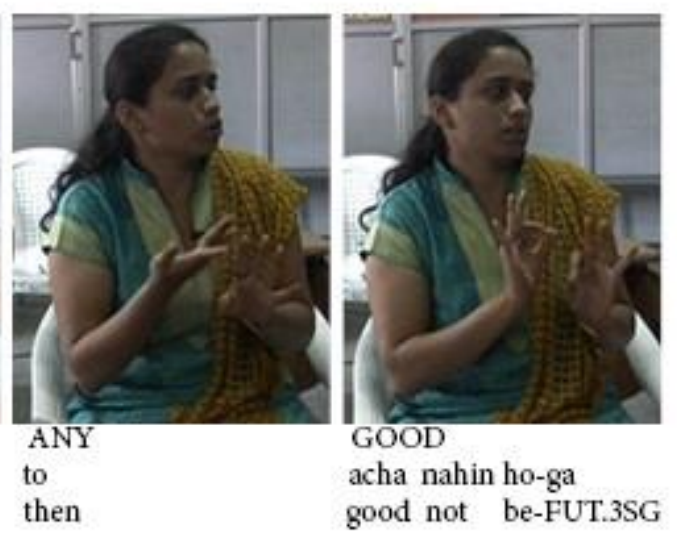

'Don't force anything; that is better'. (ISL)

'(If) you are going to force anything, that won't be good' (Hindi)

Figure 5 

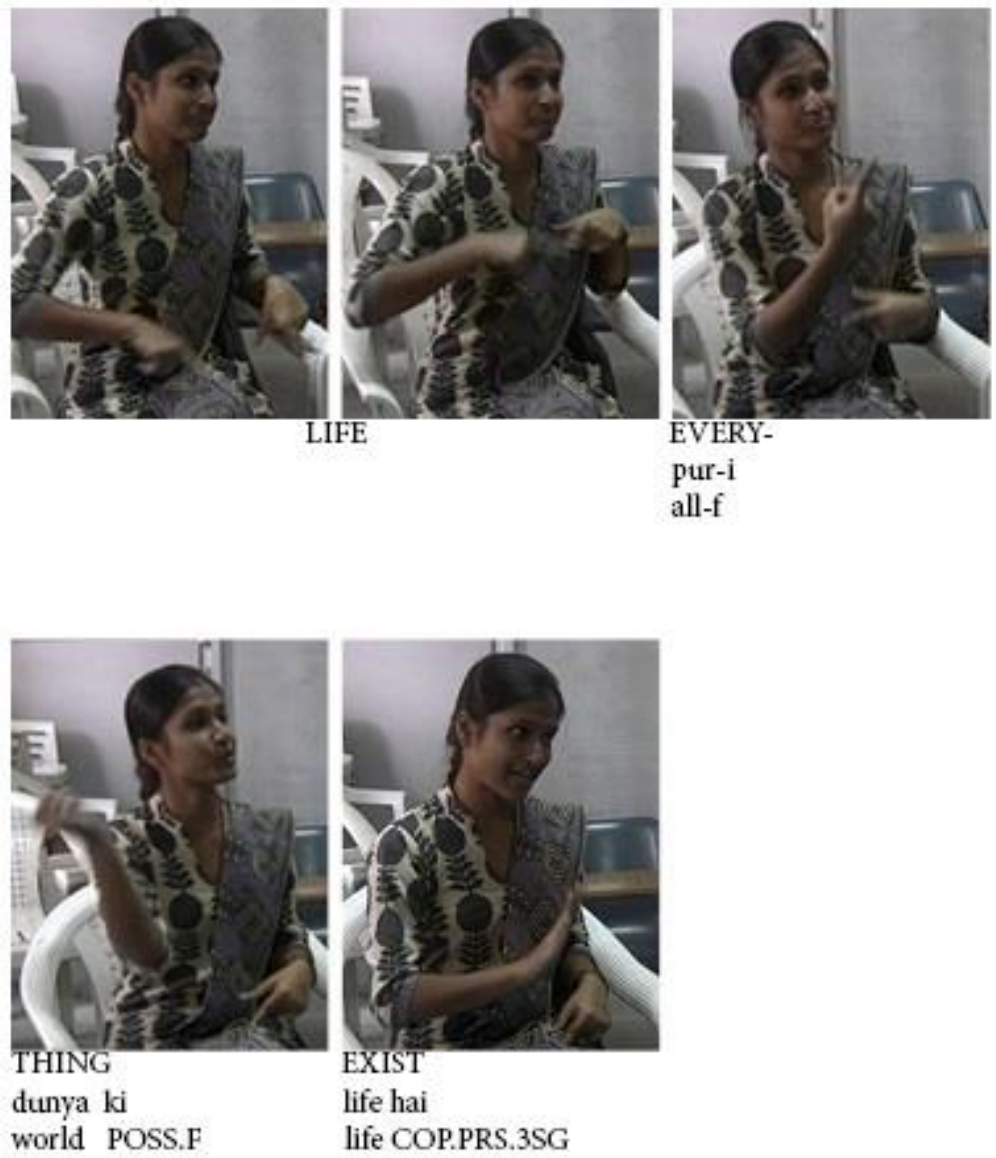

'This is life everywhere / for everyone.'

Figure 6

\subsection{SYNSEM-coded utterances}

In some utterances there are both syntactic and semantic differences between the two utterances, including multiple differences and cases where the signed and spoken utterances express different propositions. For example, when asking which class a student is currently in, the sign-speaker signs STUDY CLASS WH IX:2 while the Hindi utterance includes no word for 'study' (a semantic difference) and also has the words for 'which' and 'class' in the opposite order (a syntactic difference). Example (11) has a repetition in ISL and starts with a Hindi hesitation filler, but not all SYNSEM utterances have such dysfluencies. 
(11) IX2

FAMILY FAMILY SCHOOL GROW-UP

EXPERIENCE DEM:3pl jaise aap eh family men aur kaun kaun hain aap -ke like you.HON family in also who who COP.PRS.3PL you.HON-POSS.2PL "In your family, who else has experiences with schooling/education?" (ISL) "Like, who else is in your family?" (Hindi)

See Figure 7
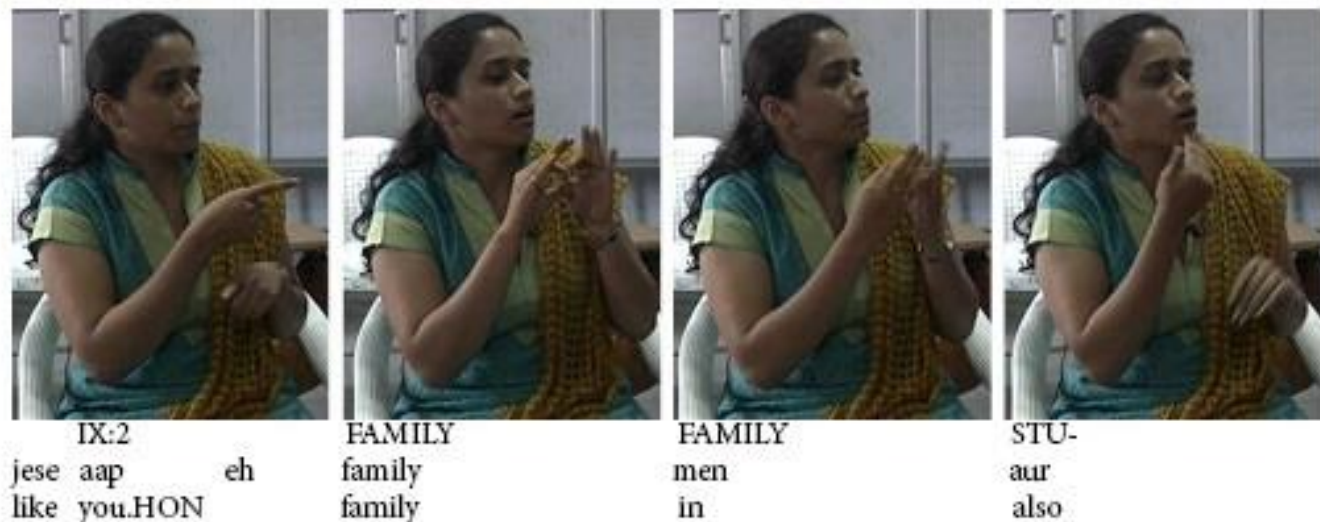

like you.HON

family

men

also
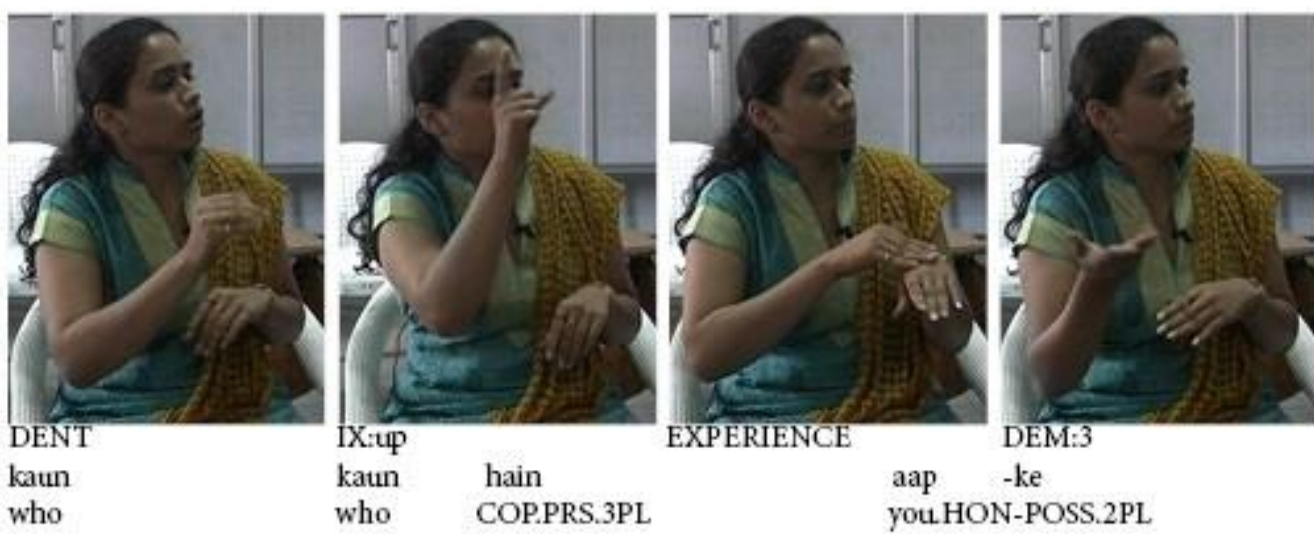

"In your family, who else has experiences with schooling/education?" (ISL)

"Like, who else is in your family?" (Hindi)

Figure 7 
More rarely, we find utterances where ISL and Hindi diverge more substantially, beyond differences between individual semantically similar or related signs. Ten utterances with such simultaneous different propositions occur in the data, including the examples in Table 6, which shows the English translation of both propositions and the coding (words in brackets are not expressed in the ISL and Hindi but are added for clarity).

Table 6. Simultaneous different propositions in ISL and Hindi

\begin{tabular}{|c|c|c|}
\hline$I S L$ & Hindi & Coding \\
\hline He starts (it) himself. & So he can do it too. & SYNSEM \\
\hline $\begin{array}{l}\text { "I am deaf and limited to only that } \\
\text { much" - no, no, (that's not the case). }\end{array}$ & $\begin{array}{l}\text { "He is deaf and so can't do anything" } \\
\text { - it's not like that }\end{array}$ & SYNSEM \\
\hline We paid someone for the rent. & We lived in a rental. & SEM \\
\hline It is the story. & This is just life. & SEM \\
\hline Half (of the students) commute. & The rest (of the students) are locals. & SEM \\
\hline $\begin{array}{l}\text { The } 10^{\text {th }} \text { (year) is linked with the } \\
\text { hearing (students) and the } 12^{\text {th }} \text { (year) is } \\
\text { linked with the hearing (students) for } \\
\text { the exams. }\end{array}$ & $\begin{array}{l}\text { The students sit the } 10^{\text {th }} \text { (year) board } \\
\text { exam and the } 12^{\text {th }} \text { (year) board exam. }\end{array}$ & SYNSEM \\
\hline
\end{tabular}

\subsection{Summary of the utterances with mismatches}

In the sign-speaking data, the large majority of the utterances are complete and grammatical in both co-occurring languages (though they may have certain peculiarities vis-à-vis monolingual Hindi or ISL, such as a different prosody; these have not been investigated in detail here). Table 7 shows a summary of the coding categories of the six sample texts produced by our participants, with a total of 180 utterances.

Table 7. Mismatched structures in sign-speaking texts 


\begin{tabular}{|c|c|c|c|c|c|c|}
\hline & & & & \multicolumn{3}{|c|}{ Mismatched structures } \\
\hline Segment & $\begin{array}{l}\text { Sign- } \\
\text { speaker }\end{array}$ & Topic & PAR & SEM & SYN & $\begin{array}{l}\text { SYN } \\
\text { SEM }\end{array}$ \\
\hline 1 & 1 & $\begin{array}{l}\text { Counselling about life chances for } \\
\text { deaf people }\end{array}$ & 14 & 6 & 3 & 5 \\
\hline 2 & 1 & $\begin{array}{l}\text { Relating a story from sign language } \\
\text { course materials }\end{array}$ & 15 & 7 & 3 & 1 \\
\hline 13 & 2 & $\begin{array}{l}\text { Presentation to visitors, further } \\
\text { information about the school }\end{array}$ & 9 & 9 & 1 & 1 \\
\hline 17 & 3 & $\begin{array}{l}\text { Counselling about life chances for } \\
\text { deaf people }\end{array}$ & 11 & 10 & 0 & 0 \\
\hline 19 & 3 & $\begin{array}{l}\text { Personal experiences of growing up } \\
\text { with deaf parents as a hearing child }\end{array}$ & 12 & 3 & 4 & 2 \\
\hline \multirow[t]{4}{*}{21} & 4 & $\begin{array}{l}\text { Interpreting and other work with } \\
\text { sign language }\end{array}$ & 13 & 11 & 0 & 1 \\
\hline & & Total parallel structures & $\begin{array}{c}74 \\
(52 \%)\end{array}$ & & & \\
\hline & & Total mismatches by category & & $\begin{array}{c}46 \\
(33 \%)\end{array}$ & $\begin{array}{c}11 \\
(8 \%)\end{array}$ & $\begin{array}{c}10 \\
(7 \%)\end{array}$ \\
\hline & & Total all mismatches & & \multicolumn{3}{|c|}{$67(48 \%)$} \\
\hline
\end{tabular}

All participants and all texts have similar percentages of overall mismatches in the data. We also observe that SYN and SYNSEM utterances are much less frequent than SEM utterances, which is perhaps related to a greater processing difficulty in the latter. In any case, the high percentage of mismatches, which taken together are nearly as frequent as parallel structures, would call for an explanation in terms of language processing.

5 Discussion and conclusions

Sign-speaking is a rare phenomenon, and virtually undocumented in the research literature.

Therefore, we start by discussing several points where the actual data go against what might be expected for sign-speaking on the basis of established knowledge, theories and assumptions.

One reasonable expectation would be that sign-speaking is demanding in terms of the processing load, and that this would be visible in the data. As exemplified in (11), we do find occasional dysfluencies, such as hesitations, fillers, and false starts. These have not been 
investigated in detail, but it is clear that they are not frequent by any means. Even in the longest text segments, there is no evidence for decrease in tempo, increase in partial or adapted ISL/Hindi, or increase in dysfluencies towards the end of the text. Thus at the present stage of research, there is little indication to suggest that the participants are under any particular pressure from a double processing load.

On the basis of what we know about bimodal communication systems such as Sign Supported English, another reasonable assumption would be that Hindi, as the main language of the surrounding hearing majority, is more fully expressed than ISL in the data. As we have seen in Section 3.2, this is the case only if the setting has skewed the output in favour of Hindi because of a primary non-signing audience, and the reverse situation, with ISL more fully realised, also occurs if signers are the primary audience, while most texts are equally balanced between ISL and Hindi. Thus the data indicate that signers use several sub-registers within sign-speaking.

Although our quantitative analysis has focused on word order, it is also obvious in the data that sign language specific structures are not suppressed due to the simultaneous presence of Hindi. This includes spatial layouts with the localisation of referents in the signing space, grammatical facial expressions, and the expression of spatial and simultaneous morphology, all of which are modality-specific sign language structures (see Meier, Cormier Quinto-Pozos, 2002; Baker \& Padden, 1978; Dikyuva 2011; Engberg-Pedersen 1993; Perniss 2012).

The coding for mismatches used in our data analysis only provides a partial picture of all the differences between Hindi and ISL because of the way in which the coding categories focus on sequential ordering of signs/words in the clause. In actual fact, the divergence between the two languages is much greater, and further aspects not included in the analysis include: 
- Semantically similar signs/words belonging to different word classes (e.g. Hindi nouns for "rent", "welcome" and inflected transitive ISL verb signs x:PAY:y, $\mathrm{x}$ :WELCOME:y).

- Difference in person reference (e.g. for generic statements, Hindi uses third person, ISL users first person). ${ }^{\mathrm{v}}$

- Differences at the discourse level (e.g. spatial locations set up for reference at the discourse level in ISL).

Finally, a possible hypothesis is that each participant may develop individual strategies to deal with the simultaneous production of two divergent languages. However, the data by and large do not support such a generalisation. ${ }^{\mathrm{vi}}$ On the contrary, the data reveal commonalities among all sign-speakers. One of these is the use of English within the trilingual situation strictly as an Embedded Language, with no consequence for grammatical structure, by all sign-speakers. However, it is less clear which language, if any, should be considered a Matrix Language. Unlike for English, the grammars of both Hindi and ISL are clearly in evidence, and either of these, or in fact both of them simultaneously, could be considered the Matrix Language(s) of any particular utterance. Another option is to assume a two-tiered structure of language contact, where English lexemes are embedded into spoken Hindi at one level, and the output is then co-produced with ISL at another level (see Figure 8 for a schematic representation of such a trilingual output). ${ }^{\mathrm{vii}}$ This view has the advantage that, unlike the combination with ISL, the combination of English and Hindi can be described with existing frameworks and compared with similar spoken language bilingual data (e.g. Si, 2010). 


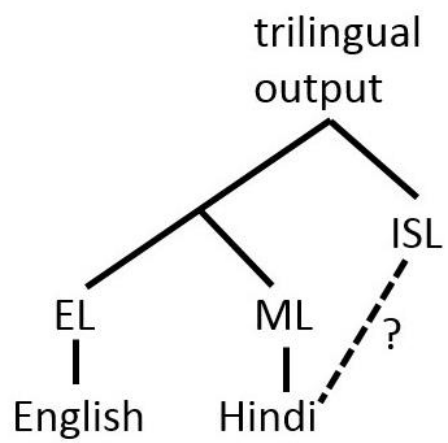

Figure 8

Finally, one might argue that the EL-ML model was developed on the basis of bilingual data with sequential code-switching rather than multilingual data with simultaneous presence of several codes, and thus the model cannot easily be applied to the current signspeaking data, which require a different conceptual analysis. In fact, the relationship between Hindi and ISL in sign-speaking does not fit any existing labels, hence the question mark in Figure 8, and the discussion of translanguaging in Section 3.2.

Perhaps the aspect of sign-speaking that is most challenging to existing theories is the high percentage of mismatches between Hindi and ISL, evident in all participants. This raises some serious questions for existing models of language production. How is it possible that two different structures, and even two different propositions, are generated apparently at the same time? Previous researchers have assumed a single computation for bimodal bilingual utterances (Donati and Branchini, 2012; Ergenç et al., forthcoming). The most detailed processing model appears in Emmorey et al. (2008). This model assumes that a Matrix Language is chosen early in production in order to provide a syntactic frame for the utterance. That is, code-blended utterances have one grammar, and one proposition is produced at a time. Moreover, signed and spoken components are assumed to be closely interlinked during 
production (at the so-called "formulator" stage). However, the data discussed here show that during the formulation of co-occurring signed and spoken utterances, it is common but not necessary for this process to be parallel; different independent structures, and different propositions, can co-occur in both modalities. The psycholinguistic processes that enable these mismatches to be managed by the sign-speaker would need to be explored in much greater depth. In any case, this research has highlighted the high level of linguistic skill that sign-speakers display in managing their multilingual and multimodal repertoires in a way that is tailored to their setting and fine-tuned to the audience.

In future research, it would also be important to circumscribe in more detail the limits of mismatches in bimodal-bilingual utterances. For instance, even where two different propositions are involved, their communicative intent is always the same. We do not find instances of two different simultaneous propositions that are unrelated to each other in content. Thus in example (9), the intention is to discourage the parent from enforcing decisions, and this is mapped onto two different propositions with biclausal structure and the negation placed in the opposite clause respectively. Moreover, we do not find any biclausal constructions where the order of the clauses is reversed, such as a pre-posed if-clause in ISL occurring with a post-posed if-clause in Hindi. All syntactic mismatches occur within a single clause.

It would also be very interesting to look in more detail at the sequencing of monolingual and bimodal-bilingual productions in this context. This is a key characteristic of most of the interactions in our data but has not been explored in this article. The notion of “chaining” (see Gynne \& Bagga-Gupta, 2013), which looks and patterns of interlinking elements from different languages and modalities in the context of visual communication, may well be fruitfully extended to the context of sign-speaking interactions. 
The data provide evidence for regarding sign-speaking as a sociolinguistically conditioned behaviour that exists in a community of practice, in terms of Eckert and McConnell-Ginet (1992), and Zeshan and Panda (2015). The bimodal-bilingual behaviour is driven by the communicative needs of participants in this particular setting, and by the signspeaker's motivation to convey the same information to all who are present, in the absence of a separate sign language interpreter. In this instance, the community of practice consists of bimodal bilinguals with very high levels in the languages of modalities who are functioning within this particular school environment and whose roles involve frequent mediation between deaf individuals and hearing non-signers. The group of people identified here is very small, and sign-speaking is by no means characteristic of sign language interpreters or professionals in deaf school contexts in general. In fact, it is not known how widespread the phenomenon of sign-speaking is in India. For this particular case study, it is therefore appropriate to speak of a micro-community of practice (cf. Zeshan \& Webster, forthcoming, on this notion). The unavailability of sign language interpreting, and the value that this institution places on ISL, both play a role in producing this particular type of bimodalbilingual behaviour. The extent of structural dissimilarity between ISL and Hindi is another important factor. Any further research must take both the sociolinguistic setting and the contributing languages fully into account.

\section{Acknowledgements:}

The research leading to these results has received funding from the European Research Council under the European Union's Seventh Framework Programme; we are grateful for funding of this research under the project "Multilingual behaviours in sign language users" (MULTISIGN), Grant Agreement number 263647.

We gratefully acknowledge the Indore Bilingual Academy for facilitating our research on their campus. Most importantly, we would like to thank our participants Neha Vishwarup, Monica Punjabi Verma, Megha Gupta, and Gaurav Verma for their generous contribution to our research. Finally, we are grateful to two anonymous reviewers for comments on the initial version of this article. 
Abbreviations:

$\_: 1, \ldots: 2, \ldots$

1SG, 2PL...

$1: \_3$

COP

DEM

f

FUT

$\mathrm{HON}$

INF

IX

IX:1

LK

NF

OBL

POSS

PROG

PRS

PST

REL

WH spatial direction of a sign to first, second and third person location person and number marking (e.g. second person plural)

spatial direction of a sign from subject to object location

copula

demonstrative sign

feminine gender

future tense

honorific

infinitive

index finger pointing

index finger point to self for first person reference

verbal linker

non-final verb form

oblique case

possessive

progressive

present tense

past tense

relative pronoun

generic content question sign

References: 
Aboh, E., Pfau, R., \& Zeshan, U. (2006): When a wh-word is not a wh-word: The case of Indian Sign Language. In: Singh, R. \& Bhattacharya, T. (eds.): The Yearbook of South Asian Languages and Linguistics. Berlin - New York: Walter de Gruyter. pp. 11-43.

Adam, R. (2012a). Language contact and borrowing. In R. Pfau, M. Steinbach \& B. Woll (eds.), Sign language: An international handbook, pp. 841-862. Berlin: De Gruyter Mouton.

Adam, R. (2012b). Unimodal bilingualism in the Deaf community: Contact between dialects BSL and ISL in Australia and the United Kingdom. Ph.D. dissertation, University College London.

Antzakas, K. (2006). The use of negative head movements in Greek Sign Language. In U. Zeshan (ed.), Interrogative and negative constructions in sign languages, pp. 258269. Nijmegen: Ishara Press.

Baker, C., \& Padden, C. A. (1978). Focusing on the nonmanual components of American Sign Language. In P. Siple (ed.), Understanding language through sign language research. Perspectives in neurolinguistics and psycholinguistics, pp. 27-58. New York: Academic Press.

Bogaerde, B. van den, \& Baker, A. (2006). Code-mixing in mother-child interaction in deaf families. Sign Language and Linguistics 8, 155-178.

Boyes Braem, P. \& Sutton-Spence, R., eds. (2001). The hands are the head of the mouth: The mouth as articulator in sign language. Hamburg: Signum.

De Vos, C. (2012). Sign-spatiality in Kata Kolok: How a village sign language inscribes its signing space. Ph.D. dissertation, Max Planck Institute for Psycholinguistics.

Dell, G., Chang, F., \& Griffin, Z. (1999). Connectionist models of language production: Lexical access and grammatical encoding. Cognitive Science 23, 517-542. 
Dikyuva, H. (2011). Aspectual non-manual expressions in Turkish Sign Language (TID). MA thesis, University of Central Lancashire.

Donati, C., \& Branchini, C. (2012). Challenging linearization: Simultaneous mixing in the production of bimodal bilinguals. In T. Biberauer \& I. Roberts (eds.), Challenges to linearization (vol. 114), pp. 93-128. Berlin: Mouton De Gruyter.

Donati, C., \& Branchini, C. (2013). Towards a grammar for code blending (and code switching). Presented at the $11^{\text {th }}$ Theoretical Issues in Sign Language Research (TISLR) Conference, London.

Eckert, P., \& McConnell-Ginet, S. (1992). Think practically and look locally: Language and gender as community-based practice. Annual Review of Anthropology 21, 461-490.

Emmorey, K., Borinstein, H., \& Thompson, R. (2005). Bimodal bilingualism: Code-blending between spoken English and American Sign Language. In J. Cohen, K. McAlister, K. Rolstad \& J. MacSwan (eds.), Proceedings of the 4th International Symposium on Bilingualism, pp. 663-673. Somerville, MA: Cascadilla Press.

Emmorey, K., Borinstein, H., Thompson, R., \& Gollan, T. (2008). Bimodal bilingualism. Bilingualism: Language and Cognition 11, 43-61.

Engberg-Pedersen, E. (1993). Space in Danish Sign Language: The semantics and morphosyntax of the use of space in a visual language. Hamburg: Signum Press.

Ergenç, İ., İşsever, S., Makaroğlu, B., \& Dikyuva, H. (2014). Türk İşaret Dili (TIDD) - Türkçe Çift-kanallı İkidilliliğinde Dilbilgisel Görünümler. [Linguistic aspects of Turkish sign language-Turkish bimodal bilingualism]. Presented at the $17^{\text {th }}$ International Conference on Turkish Linguistics, Rouen, France.

García, O., and Wei, L. (2014). Translanguaging: Language bilingualism and education. Basingstoke: Palgrave MacMillan. 
Gullberg, M. (2011). Multilingual multimodality: Communicative difficulties and their solutions in second-language use. In J. Streeck, C. Goodwin \& C. LeBaron (eds.), Embodied interaction: Language and body in the material world, pp. 137-151. Cambridge: CUP.

Gynne, A. \& Bagga-Gupta, S. (2013). Young people's languaging and social positioning. Chaining in "bilingual" educational settings in Sweden. Linguistics and Education 24:4, pp. 479-496.

Hendriks, B., \& Dufoe, S. (2014). Non-native or native vocabulary in Mexican Sign Language. Sign Language and Linguistics 17, pp. 20-55.

Hiddinga, A., \& Crasborn, O. (2011). Signed languages and globalization. Language in Society 40:4, pp. 483-505.

Kubus, O. (2008). An analysis of Turkish Sign Language (TID) phonology and morphology. Masters thesis, Middle East Technical University, Ankara.

Kubus, O., \& Hohenberger, A. (2011). The phonetics and phonology of TID (Turkish Sign Language) bimanual alphabet. In R. Channon \& H. van der Hulst (eds.), Formational units in sign languages, pp. 43-63. Berlin: Mouton de Gruyter \& Nijmegen: Ishara Press.

Levelt, W. J. M. (1989). Speaking: From intention to articulation. Cambridge, MA: MIT Press.

Liddell, S. K. (2003). Grammar, gesture, and meaning in American Sign Language. Cambridge: Cambridge University Press.

Lucas, C., \& Valli, C. (1992). Language contact in the American deaf community. New York: Academic Press.

Meier, R.P., Cormier, K., \& Quinto-Pozos, D., eds. (2002). Modality and structure in signed and spoken languages. Cambridge: Cambridge University Press. 
Muysken, P. (2000). Bilingual speech: A typology of code-mixing. Cambridge: Cambridge University Press.

Myers-Scotton, C. (2002). Contact linguistics: Bilingual encounters and grammatical outcomes. Oxford: Oxford University Press.

Nonaka, A. (2012). Sociolinguistic sketch of Ban Khor and Ban Khor Sign Language. In U. Zeshan \& C. de Vos (eds.), Village sign languages - Anthropological and linguistic insights. Sign Language Typology Series No. 4, p. 376. Berlin: De Gruyter Mouton \& Nijmegen: Ishara Press.

Otheguy, R., García, O., and \& Reid, W. (2015). Clarifying translanguaging and deconstructing named languages: A perspective from linguistics. Applied Linguistics Review 6 (3):281-307.

Perniss, P. M. (2012). Use of sign space. In R. Pfau, M. Steinbach, \& B. Woll (eds.), Sign language: An international handbook, pp. 412-431. Berlin: Mouton de Gruyter.

Quadros, R., Lillo-Martin, D., Koulidobrova, H., \& Chen Pichler, D. (2013). Noun phrases in KODA bimodal bilingual acquisition. Presented at the $11^{\text {th }}$ Theoretical Issues in Sign Language Research (TISLR) Conference, London.

Quinto-Pozos, D. (2002). Contact between Mexican Sign Language and American Sign Language in two Texas border areas. Ph.D. dissertation, University of Texas at Austin.

Quinto-Pozos, D. (2008). Sign language contact and interference: ASL and LSM. Language in Society 37, 161-189

Quinto-Pozos, D. (2009). Code-switching between sign languages. In B. Bullock \& J. Toribio (eds.), The handbook of code-switching, pp. 221-237. Cambridge: Cambridge University Press. 
Quinto-Pozos, D. \& Adam, R. (2015). Sign languages in contact. In A. Schembri \& C. Lucas (eds.), Sociolinguistics and Deaf Communities, pp. 29-60. Cambridge: Cambridge University Press.

Roos, C. (2014). A sociocultural perspective on young deaf children's fingerspelling: An ethnographic study in a signing setting. Deafness and Education International 16, 86107.

Sandler, W. (1999). The Medium and the Message: Prosodic Interpretation of Linguistic Content in Israeli Sign Language Sign Language \& Linguistics, Vol. 2, No. 2:187215.

Schembri, A. (2010). Documenting sign languages. In P. Austin (ed.), Language documentation and description volume 7: Lectures in language documentation and description. pp. 105-143. London: School of African and Oriental Studies.

Si, A. (2010). A diachronic investigation of Hindi-English code-switching, using Bollywood film scripts. International Journal of Bilingualism 15, 388-407.

Sutton-Spence, R. (1994). Where can you see language contact between English and British Sign Language? The use of the manual alphabet in place-names and BSL. Report, Centre for Deaf Studies, University of Bristol.

Sutton-Spence, R., \& Woll, B. (1998). The linguistics of British Sign Language. Cambridge: Cambridge University Press.

Wilbur, R. B. (2000). Phonological and prosodic layering of non-manuals in American Sign Language. In K. Emmorey \& H. Lane (eds.), The signs of language revisited: An anthology to honour Ursula Bellugi and Edward Klima, pp. 213-244. Mahwah, NJ: Lawrence Erlbaum. 
Wilbur, R. B., \& Petersen, L. (1998). Modality interactions of speech and signing in simultaneous communication. Journal of Speech, Language and Hearing Research $41,200-212$.

Wittenburg, P., Brugman, H., Russel, A., Klassmann, A., \& Sloetjes, H. (2006). ELAN: A professional framework for multimodality research. Proceedings of the $5^{\text {th }}$ International Conference on Language Resources and Evaluation (LREC), pp. 15561559. Available at: http://www.Irec-conf.org/proceedings/lrec2006/pdf/153_pdf.pdf [accessed 13 October 2015].

Zeshan, U., \& Panda, S. (2015). Two languages at hand: Code-switching in bilingual deaf signers. Sign Language and Linguistics 18, 90-131.

Zeshan U. (2004a): Indo-Pakistani Sign Language. In: Strazny, P. (ed.): Encyclopedia of Linguistics. New York: Fitzroy Dearborn. pp. 524-528.

Zeshan, U. (2004b). Interrogative constructions in sign languages - Cross-linguistic perspectives. Language 80.1, 7-39.

Zeshan, U. \& Webster, J. (forthcoming). Sign Multilingualism. Sign Language Typology Series No. 7. Berlin: De Gruyter Mouton \& Lancaster: Ishara Press.

\footnotetext{
'Some examples include Italiano signato ("Signed Italian"), Lautsprachbegleitende Gebärden ("Speechaccompanying Signs") in Germany, or Nihongo taiou shuwa ("Signed Japanese").

ii Examples include the spoken language utterance with an interlinear transcription, and capital letter glosses in English representing the signs, as is common practice in sign language linguistics. The morphology of signs is integrated into the glosses, making a separate interlinear transcription unnecessary. The vertical alignment between lines reflects the temporal co-occurrence of signing and speaking. Screenshots from the video recordings are used in some of the examples. All abbreviations are listed at the end of the article.

iii This text is one of those with a very low frequency of English words (one word every 6 seconds on average). It would be interesting to examine whether a deaf-directed style correlates with a low frequency of English words, but more data would be needed to be able to ascertain this.
} 
iv See the supplementary video file for an example of a text segment with equally complete expression of ISL and Hindi and a high level of mismatches between the Hindi and ISL outputs.

${ }^{v}$ The whole narrative in segment 2 is told in the third person in Hindi, but in the first person in ISL, following the storytelling conventions in the two languages.

${ }^{v i}$ The only noticeable difference between individual sign-speakers is the extent to which they use SYN and SYNSEM coded utterances (see Table 6); some participants use those more than others, but there are not enough utterances to reach a conclusion and this point would need further research. 